\title{
Post-Operative Outcome in Patients Who Have Undergone Lateral Pancreaticojejunostomy for Chronic Pancreatitis
}

\author{
Savalia Abhishek J. ${ }^{1}$, Modi Pankaj R. ${ }^{2}$, Gahlot Garima B. ${ }^{3}$ \\ ${ }^{1,2}$ (Dept. of General Surgery, Civil Hospital, Ahmedabad, India) \\ 3 (Department of Microbiology, Civil Hospital, Ahmedabad, India)
}

\begin{abstract}
AIM- To assess the benefit of Lateral Pancreaticojejunostomy (LPJ) in patients with chronic pancreatitis.

MATERIALS AND METHODS-45 patients of chronic pancreatitis at Civil hospital of Ahmedabad, with Major pancreatic duct of $6 \mathrm{~mm}$ or more and not responding to analgesics, were treated by Lateral Pancreaticojejunostomy. Follow up of the operated patients was done over three years either in person or by telephonic interview. Data was analysed using chi-square test.

RESULTS- Immediate Post-op morbidity rate was 13.3\%; mortality rate was 7.14\%. 1 patient died later secondary to chronic pancreatitis. Rehospitalization for recurrent attacks of pancreatitis and pain was necessary in $16.7 \%$ of patients. $7 \%$ patients required revision surgery for chronic pancreatitis. Overall Health status was characterized as good in 16, fair in 20 and poor in 6 patients. Insulin/oral hypoglycemics use continued in $11.9 \%$ patients; however the daily dose was decreased following surgery. One patient was diagnosed as having Diabetes Mellitus 3 months after surgery. Pancreatic enzyme supplementation was required in $31 \%$.

CONCLUSION-Adequate major pancreatic duct decompression is the key to successful surgery. Morbidity and mortality rate was comparable to other studies. Pain relief is near complete in the first year. However the pain recurs as the years pass due to progression of the disease. Overall health status post-surgery improved. Surgeryfailed to reverse exocrine or endocrine insufficiency.

Keywords: Chronic pancreatitis, endocrine insufficiency, exocrine insufficiency,Lateral Pancreaticojejunostomy, pain
\end{abstract}

\section{Introduction}

Pancreatitis, depending upon duration of the disease, is chiefly of two types - Acute and Chronic. Chronic Pancreatitis is"A continuing inflammatory disease of the pancreas, characterized by irreversible morphological changes, and typically causing pain and/or permanent loss of function."(1)Chronic pancreatitis has three debilitating features pain,steatorrhoea and diabetes mellitus.

The principal aim in management of chronic pancreatitis is to alleviate pain, which is the main symptom of this disease, using one or more of the following strategies $(1,2,3)-$

$\checkmark$ Reducing secretion (Enzyme therapy) and/ or decompress the Major Pancreatic Duct(MPD) [Lateral Pancreaticojejunostomy(LPJ)];

$\checkmark$ Resecting the focus of chronic inflammatory disease, most commonly located in the head region of pancreas (Frey's procedure, Berger's procedure, Whipple's surgery, Distal pancreatectomy);

$\checkmark$ Interrupting the transmission of afferent neural impulses through neural ablative procedures like celiac plexus block;

And thus, ultimately improve the health status of the patient.

The aim of this study is to determine the post op outcome in terms of improvement in following parameters

Pain,

Over-all Health status,

Exocrine insufficiency,

Endocrine insufficiency,

Morbidity and mortality.

\section{Materials and Methods}

45 patients of chronic pancreatitis at Civil Hospital of Ahmedabad with Major pancreatic duct of $6 \mathrm{~mm}$ or more and not responding to analgesics were treated surgically by doing Lateral Pancreaticojejunostomy.

Follow up of the operated patients was done over three years either in person or by telephonic interview. Pain was quantified using Visual Analogue Scale Health status was classified as good, fair, or poor based on a score determined by assigning one point for each of the following:

Analgesic use, 
Alcohol use,

Re-hospitalization for complications of pancreatitis,

Subsequent operations for complications of chronic pancreatitis,

associated major medical co-morbidity,

Unemployment.

Patients also were asked to provide a personal assessment of health as good, fair, or poor and were assigned one point for fair health and two points for poor health. Patients in good health scored 0 to 3 points, fair health 4 to 6 points and poor health more than 6 points. (4)

The observed data were statistically analyzed by Chi-square test.

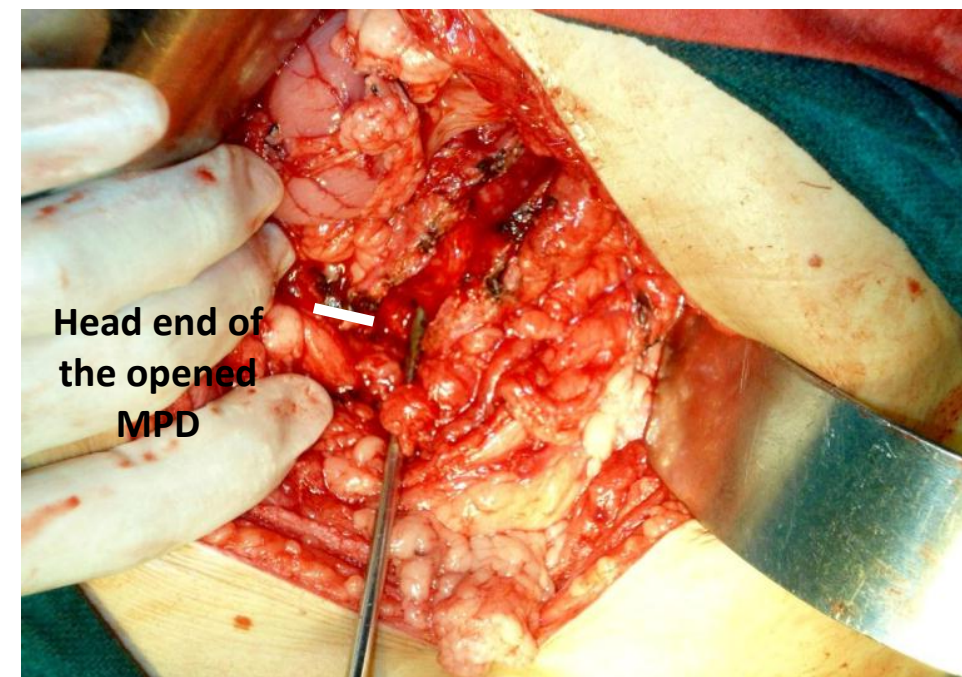

Figure 2 Opened Major Pancreatic Duct (MPD)

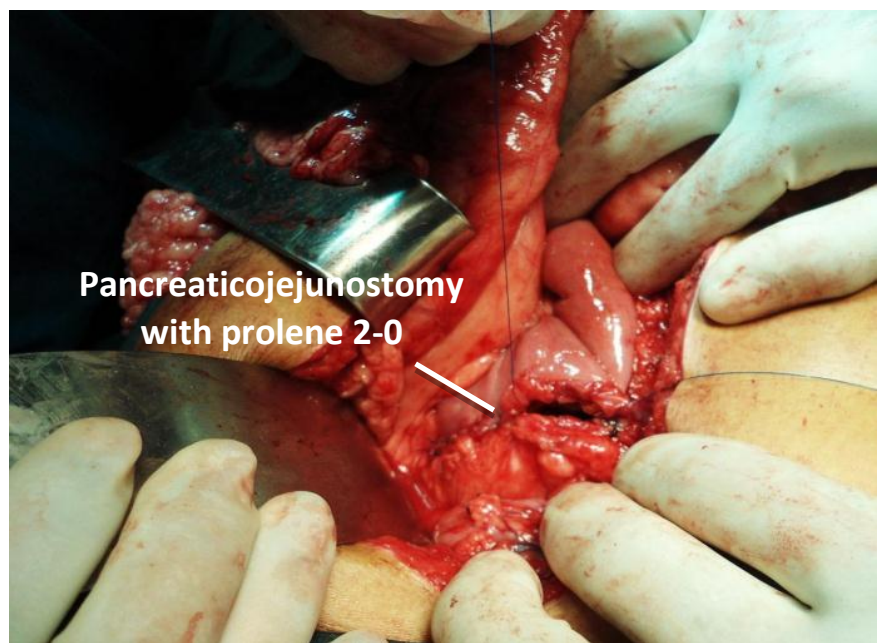

Figure 1 Pancreaticojejunostomy done in 1 layer with prolene 2-0

\section{Patient Demographics}

\section{Results}

Total 45 patients were followed post operatively. The mean age of the 45 patients ( 30 men, 15 women) was 35.7 years (range, 8 to 65 years age). The causes of chronic pancreatitis were alcohol abuse in 31 and unknown in 14. Thus, alcohol accounted for $69 \%$ of the cases.

\section{Operative Procedures}

All patients underwent LPJ.In most of the patients, cholecyctectomy was done, even in absence of gall stones in investigations, as a prophylactic step. One patient had first Duval's procedure done, which was later converted into LPJ.6 patients $(13.3 \%)$ had associated complications of chronic pancreatitis. They were managed as in Table 1. 
Table 1Variation in LPJ in 6 patients

\begin{tabular}{|c|c|c|}
\hline No. of pts. & Complication & Surgery \\
\hline 1 & CBD stone & LPJ + cholecystectomy + Choledochoduodenostomy \\
\hline 1 & CBD stricture & LPJ + cholecystectomy + choledochojejunostomy \\
\hline 4 & Pseudocysts & $\begin{array}{c}\text { Inclusion of pseudocyst in LPJ; } \\
\text { Drainage of cyst }\end{array}$ \\
\hline
\end{tabular}

\section{EARLY POSTOPERATIVE OUTCOME (30 days)}

\section{Pain Relief}

Pain relief in the immediate postoperative period was uniformly impressive. All thepatients were completely relieved of the pain.

Early Postoperative Complicationswere seenin 6 Of 45 Patients. They are summarized in Table 2.

Of these, 3died within 30 days of surgery.

Thus,postoperative complication rate was $13.3 \%$ and operative mortality rate $7.14 \%$.

Table 2

\begin{tabular}{|l|l|l|l|}
\hline & Complication & Management & Result \\
\hline 1 & Anastomotic leak & $\begin{array}{l}\text { Expectant, nonoperative } \\
\text { Management }\end{array}$ & Death \\
\hline 2 & $\begin{array}{l}\text { Pancreatic fistula + Intestinal } \\
\text { obstruction after 15 days }\end{array}$ & $\begin{array}{l}\text { Conservative management of fistula and } \\
\text { adhesiolysis for obstruction }\end{array}$ & Resolved \\
\hline 3 & Fecal fistula & $\begin{array}{l}\text { Expectant, nonoperative } \\
\text { management }\end{array}$ & Resolved in 20 days \\
\hline 4 & $\begin{array}{l}\text { Abdominal distension, pain - ? } \\
\text { obstruction/ anastomotic leak }\end{array}$ & Coudn't avail tertiary care & Died at home \\
\hline 5 & Cardiac failure & $\begin{array}{l}\text { intensive } \\
\text { care unit management } \\
\text { shofuse bleeding PR, hemorrhagic } \\
\text { Erosion of Common Hepatic artery } \\
\text { with bleeding into GIT }\end{array}$ & $\begin{array}{l}\text { Blood transfusion } \\
\text { CECT abdomen and angiography } \\
\text { Embolisation of common hepatic artery }\end{array}$ \\
\hline
\end{tabular}

\section{LATE OUTCOME}

\section{Pain Relief}

Table 3Long term Pain relief

\begin{tabular}{|l|l|l|l|}
\hline & First year & Second year & Third year \\
\hline No Pain & $40(95.3 \%)$ & $21(91.3 \%)$ & $6(85.7 \%)$ \\
\hline Mild to moderate occassional Pain & 2 & 2 & 1 \\
\hline Severe pain* & 0 & 0 & 0 \\
\hline Total & 42 & 23 & 7 \\
\hline
\end{tabular}

* 3 patients developed severe (VAS score 8) pain after surgery. Revision LPJ was done in 2 patients, and Frey's procedure in another for a new inflammatory mass in head region. Post surgery, the pain subsided in all three.

Overall pain relief results (Table 4)

Table 4

\begin{tabular}{|l|l|}
\hline Amount of pain relief & Number of patients $(\mathbf{n}=\mathbf{4 2})$ \\
\hline Complete & $38(90.5 \%)$ \\
\hline Substantial & $4(9.5 \%)$ \\
\hline Minimal & - \\
\hline Total & 42 \\
\hline
\end{tabular}

Over all Health Status with Alcohol, Narcotic, Insulin, And Pancreatic Enzyme Use In Surviving Patients (Table 5, Fig.3)

Table 5

\begin{tabular}{|l|l|l|l|l|l|}
\hline & $\begin{array}{l}\text { Health } \\
\text { Status }\end{array}$ & Alcohol & Analgesics & $\begin{array}{l}\text { Insulin / oral } \\
\text { hypoglycemic } \\
\text { drug }\end{array}$ & Enzymes \\
\hline Good & 16 & $2\left(6.6^{*}\right)$ & 0 & $1(6.3)$ & $2(12.5)$ \\
\hline Fair & 20 & $4(20)$ & $3(15)$ & $2(10)$ & $5(25)$ \\
\hline Poor & 6 & $4(66.7)$ & $4(66.7)$ & $3(50)$ & $6(100)$ \\
\hline Total & 42 & $10 / 31(32.6)$ & $7(16.7)$ & $6(14.3)$ & $13(31)$ \\
\hline
\end{tabular}


* Percentage

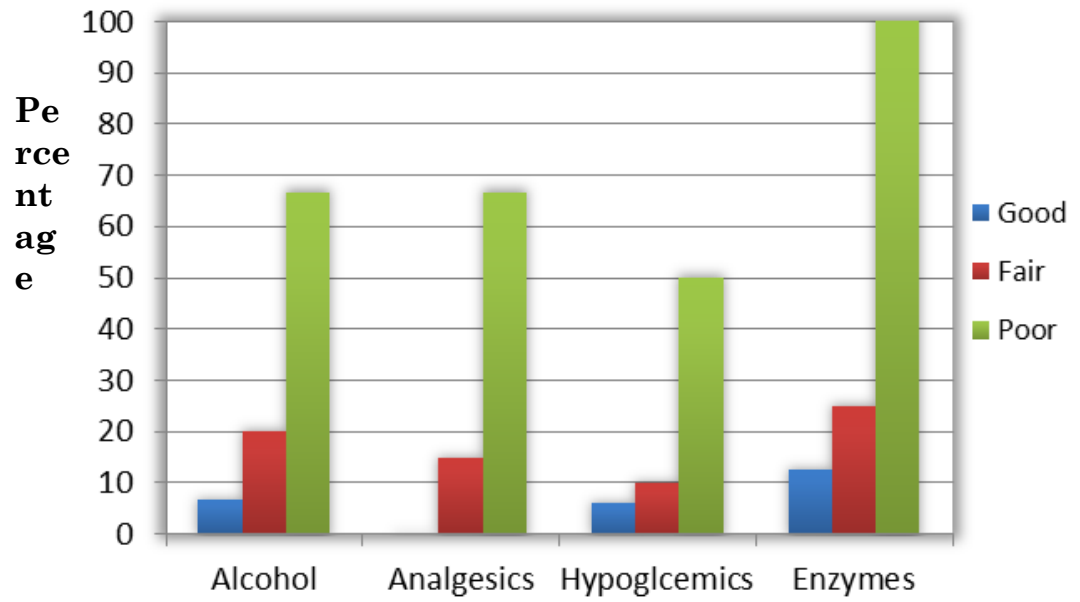

Point to be noted was that it was a uniform finding that in all preexisting diabetics, the required dose of hypoglycemics was decreased post surgery.

However, the exocrine insufficiency either persisted/ worsened/ developed post surgery.

Average weight gainin patients having good health status was $7.2 \mathrm{~kg}$, in those having fair health status was 4.8 $\mathrm{kg}$ and in those having poor health status was $2.5 \mathrm{~kg}$. Overall, average weight gain was $6.2 \mathrm{~kg}$.

RehospitalizationFor Medical Disorders In Survivors

(7/42 PATIENTS, $16.7 \%$ )

$7(16.7 \%)$ of the 42 surviving patients required one or more hospital admissions during follow-up. Reasons for hospitalization are shown in Table 6.

Table 6Rehospitalization

\begin{tabular}{|c|c|}
\hline No. of pts. & Cause \\
\hline 5 & Pain/ chronic pancreatitis \\
\hline 1 & Malnutrition, Psychiatric disorder \\
\hline 1 & Stitch granuloma \\
\hline
\end{tabular}

5 of the patients were admitted for management of conditions related to pain owing to chronic pancreatitis. Recurrent attacks of pancreatitis usually were managed conservatively.

However three patients with recurrent pain required revision surgery for same.

Revision surgery For Chronic Pancreatitis In 3 Patients (Table 7)

Table 7

\begin{tabular}{|l|l|l|l|}
\hline Pts. & Previous surgery & Reason & Surgery \\
\hline 1 & LPJ & Recurrent pain & Redo LPJ + cholecystectomy \\
\hline 1 & Duval's procedure & Recurrent pain & LPJ \\
\hline 1 & LPJ & Recurrent pain & Frey's Procedure \\
\hline Total 3 & & & \\
\hline
\end{tabular}

One patient had undergone LPJ previously. Post surgery patient was asymptomatic. the pain recurred after 2 years and was severe. Investigations showed incomplete MPD decompression by first surgery. So, she had to undergo redo-LPJ. The duct was found to be opened only in the head region - rest of the MPD was opened up during second surgery and LPJ done. Following second surgery, patient had persistent pain, but of decreased severity, in immediate post op period for 1 to 2 months. Thereafter the pain disappeared completely.

Second patient underwent Duval's procedure the first time. A year later the pain recurred and was severe, not relieved by analgesics. MRCP showed persistent duct obstruction in proximal portion and had to be operated upon again. After doing LPJ, the pain disappeared completely and patient's overall health status also improved. The third patient had undergone LPJ previously. Owing to recurrent pain she had had a CT scan done which showed an inflammatory mass in head region. For this, a Frey's procedure was done and post operatively, patient is doing well. 


\section{Mortality}

4 out of 45 patients $(8.9 \%)$ died during the follow-up period.

3 died within 30 days of surgery due to above mentioned complications of surgery;

One died 2 years after surgery following chronic malnutrition and progression of chronic pancreatitis. Cause of death in each mentioned in Table 8

Table 8

\section{Patient demographics}

\section{Discussion}

The age of patients having operations for chronic pancreatitis generally falls in the mid-40s with a range of 29 to 66 years ${ }^{(5,6)}$ Our mean patient age was 36 years owing to three of the patients in our study being of less than 15 years age.. The study by Leger et al. ${ }^{(7)}$ also had a mean age of 39.6 years.

Pancreatitiswasmore common in males, a uniform finding in all studies. ${ }^{(1,2)}$

\section{Causes}

Alcoholwas the most common cause of chronic pancreatitis as supported by all studies ${ }^{(1,2,6)}$ This population often have other substance abuse problems including tobacco, narcotics, and tranquilizing agents, that also may affect their health status. Many of these patients have a poor health status when first seen.

Malnutrition is common and must be corrected before operation.

\section{Patients were selected for LPJ on the basis of -}

$\checkmark$ unrelenting pain not relieved by analgesics;

$\checkmark$ evidence of a dilated pancreatic duct (6 $\mathrm{mm}$ or more);

$\checkmark$ presence of pancreatic duct calculi and/or stricture ${ }^{(1,2,3,4)}$

\section{Operative Procedure}

We used the Partington-Rochelle modification of Peustow's procedure for LPJ in all cases.

In all cases, the duct incision was carried over the full length of the dilated duct. The ductal incision in the head area was carried as close as possible to the duodenal wall taking care to avoid the pancreatoduodenal arcade. Several authors ${ }^{(8,9)}$ have emphasized the importance of an adequatelength of incision over the major pancreatic duct to assure complete drainage, a fact which we personally experienced in 2 patients.

In our experience, incomplete ductal decompression was most likely to occur in the head of the gland a finding also described by other authors. ${ }^{(10)}$ This segment of the gland was considered the most probable source of persistent or recurrent pancreatitis in the postoperative period.

Most pseudocysts located in the head and body of the gland can be incorporated into the LPJ. ${ }^{(1)}$

\section{Morbidity and Mortality}

Lateral pancreaticojejunostomy is a relatively safe procedure despite its magnitude. Postoperative morbidity rate of $13.3 \%$ was within an acceptable range.

Table 9Comparison of Morbidity rate

\begin{tabular}{|c|c|c|c|}
\hline & Current study (LPJ) & Izbicki et al. ${ }^{(17)}$ (LPJ group) & Izbicki et al. ${ }^{\left({ }^{17}\right)}$ (PPPD* group) \\
\hline & $6 / 45(13.3 \%)$ & $6 / 31(19.4 \%)$ & $16 / 30(53.3 \%)$ \\
\hline
\end{tabular}

*Pylorus Preserving Pancreaticoduodenectomy

On comparing our rate with LPJ group in Table $9, \mathrm{X}^{2}$ value is 0.5 , which is less than $6.64\left(\mathrm{X}^{2}\right.$ valueat $\mathrm{p}=0.01$ at 1 degree of freedom). Hence, the difference is not significant.

On comparing with PPPD group, $\mathrm{X}^{2}$ value is 14.7 , which is more than $6.64\left(\mathrm{X}^{2}\right.$ valueat $\mathrm{p}=0.01$ at 1 degree of freedom).Hence, LPJ has significantly less morbidity than PPPD.

Our post op mortality rate of $7 \%$ was comparable with Greenlee's mortality rate of $4 \% . X^{2}$ value is 0.075 , which is less than $6.64\left(\mathrm{X}^{2}\right.$ value at $\mathrm{p}=0.01$ at 1 degree of freedom).

Mortality rates in the range of $0 \%$ to $5 \%$ have been reported in several studies. ${ }^{(4,5,6,10,12)}$

\section{Pain relief}

Immediately post-surgery, complete pain relief was seen in $100 \%$ patients. This was also seen in study by Adams D B et al. ${ }^{(4)}$ Overall, pain relief was comparable with Sato's ${ }^{(21)}$ study. See Table 10 
Table 10

\begin{tabular}{|l|l|l|}
\hline & Current study & Sato et al. $^{(21)}$ \\
\hline Complete pain relief & $38(90.5 \%)$ & $39(90.7 \%)$ \\
\hline Substantial relief & $4(9.5 \%)$ & $4(9.3 \%)$ \\
\hline Minimal relief & 0 & 0 \\
\hline Total & 42 & 43 \\
\hline
\end{tabular}

Schwartz Textbook of Surgery says that pain relief achieved in first few years ranges from $75 \%$ to $85 \%{ }^{(1)}$. However further followup is necessary to determine long term pain relief.

\section{Overall health status}

Overall health was statistically better than a similar study by Adam D B et al ${ }^{(4)}$.(Table11)

Table 11

\begin{tabular}{|l|l|l|}
\hline Overall Health status & Present study & Adams D B et al. (4) \\
\hline Good & 16 & 15 \\
\hline Fair & 20 & 19 \\
\hline Poor & 6 & 28 \\
\hline Total & 42 & 62 \\
\hline
\end{tabular}

$\mathrm{X}^{2}$ value17.4, which is more than $9.21\left(\mathrm{X}^{2}\right.$ valueat $\mathrm{p}=0.01$ at 2 degrees of freedom). However, a longer duration of follow up is necessary for better comparison.

Alcohol abuse continued in 10 out of 31 alcoholic patients and 8 out of these 10 patients belonged to fair to poor category. Thusabstinence is associated with a better outcome after LPJ also noted by Little JM et al. ${ }^{(14)}$.

Analgesic, insulin and enzymes use also clearly increased as the health status deteriorated. This was also noted by Adam D B et al. ${ }^{(4)}$.

Prevalence of Endocrine and Exocrine insufficiences post-op was comparable with Leger's study. ${ }^{(7)}$ (Table 12)

Table 12

\begin{tabular}{|l|l|l|l|}
\hline Study & No. of Cases & $\begin{array}{l}\text { Diabetes } \\
\text { (no. of pts.) }\end{array}$ & Exocrine Insufficiency \\
\hline Present study & 45 & $6(13.3 \%)$ & $13(31)$ \\
\hline Leger et al. $^{(7)}$ & 148 & $19(12.8 \%)$ & $47(31.8 \%)$ \\
\hline
\end{tabular}

Point to be noted was that it was a uniform finding that in all pre-existing diabetics, the required dose of hypoglycemics was decreased post-surgery, a finding also shared by Izbicki et al. (17).

However the exocrine function didn't improve post surgery. In fact it deteriorated over period of time (due to progression of the disease), a view shared by all studies. . $^{8.10 .15)}$

Average weight gaindecreased as the health status decreased. Overall average weight gain was $6.2 \mathrm{~kg}$. Similar study by Nealon et al. ${ }^{(23)}$ showed $4.2 \mathrm{~kg}$ average weight gain.

Rehospitalizationin surviving patients is mostly for recurrent attacks of pancreatitis and pain. Studies which had been done over 10-20 years period, like those by Izbicki et al. and Adams et al., showed 48\% and 59\% readmission rates respectively.

\section{Revision surgery}

In the study by Adams D B et al. ${ }^{(4)}, 5$ of 85 patients required revision LPJ for distal MPD stenosis, possibly overlooked during first surgery.In our study $3 / 42$ required revision surgery. $\mathrm{X}^{2}$ value is 0.08 , which is less than 6.64 (X2 value at $\mathrm{p}=0.01$ at 1 degree of freedom). Hence, the difference is not significant and revision surgery rate in this study is similar to that in Adams' study.

\section{Conclusion}

LPJ is the surgery of choice for chronic pancreatitis patients with pain not releived by NSAIDs, dilated MPD ( $\geq 6 \mathrm{~mm})$, with or without MPD stones and no inflammatory mass in head region.

Adequate MPD decompression is the key to successful surgery.

Complete/ substantial Pain relief is seen in 85 to $96 \%$ patients for the first few years, however the pain recurs as the years pass due to progression of the disease. Further followup is required to assess long term pain relief following surgery.

The operation itself doesn't reverse the endocrine orexocrine function of pancreas.

Overall health statuspost-surgery improved, provided the patient remained abstinent.Analgesics, alcohol, hypoglycemics and enzymes consumption increased as the health staus deteriorated. Weight of the patients also increased post-surgery. 
Postoperative complication rate and mortality rate was comparable with other studies.

\section{References}

[1]. Schwartz's Principles of Surgery. (2010), McGraw Hill.

[2]. Sabiston Textbook of Surgery. (2008), Saunders.

[3]. Mastery of Surgery. (2007), LWW.

[4]. Adams D B, Ford M C, Anderson M C. Outcome after lateral pancreaticojejunostomy for chronic pancreatitis. Department of Surgery, Medical University of South Carolina, Charleston, South Carolina

[5]. Mannell A, Adson MA, Mcllrath DC, Ilstrup DM. Surgical Management of Chronic Pancreatitis: long-term results in 141 patients. BrJSurg 1988 75:467-472.

[6]. Greenlee HB, Prinz RA, Aranha GV. Long-term results of side-to side pancreaticojejunostomy. World J Surg 1990; 14:70-76.

[7]. Leger, L. and Lenriot, J. P.: Five to Twenty Year Follow-up After Surgery for Chronic Pancreatitis in 148 Patients. Ann. Surg., 184:185, 1974.

[8]. Way LW, Gadacz T, Goldman L. Surgical treatment of chronic pancreatitis. Am J Surg 1974; 127: $202-209$.

[9]. Jordan GL, Strug BS, Crowder WE. Current status of pancreatojejunostomy in the management of chronic pancreatitis. Am J Surg 1977; 133:46-5 1.

[10]. Bradley EL III. Long-term results of side-to side pancreaticojejunostomy. World J Surg 1990; $14: 70-76$.

[11]. White T T, Slavotinek A H. Results of surgical treatment of chronic pancreatitis. Ann Surg 1979; 189:217-224.

[12]. Proctor HJ, Mendes OC, Thomas CG, Herbst CA. Surgery for chronic pancreatitis: drainage versus resection. Am J Surg 1984; 484:754-759.

[13]. Amman RW, Akovbiantz A, Largiader F, Schueler G. Course and outcome of chronic pancreatitis. Gastroenterology 1984; $86: 820-828$

[14]. Little JM. Alcohol abuse and chronic pancreatitis. Surgery 1987; 101:357-360.

[15]. WarshawA L, Popp J W Jr, Schapiro RH. Long-term patency, pancreatic function, and pain relief after lateral pancreaticojejunostomy for chronic pancreatitis. Gastroenterology 1980; 79:289-293.

[16]. Frey CF, Child CG, Fry W. Pancreatectomy for chronic pancreatitis. Ann Surg 1976; 184:403-413.

[17]. Izbicki JR, Bloechle C, Knoefel WT, Kuechler T, Binmoeller KF, Broelsch CE. Duodenum-preserving resections of the head of the pancreas in chronic pancreatitis: a prospective randomized trial. Ann Surg 1995; 221:350-358.

[18]. Puestow CB, Gillesby WJ. Retrograde surgical drainage of pancreas for chronic relapsing pancreatitis. Arch Surg 1958; 76:898907.

[19]. Partington PF, Rochelle REL. Modified puestow procedure for retrograde drainage of the pancreatic duct. Ann Surg 1960; 152:1037-1043.

[20]. DuVal MK Jr. Caudal pancreatico-jejunostomy for chronicrelapsing pancreatitis. Ann Surg 1954; 140:775-785.

[21]. Sato, T., Saitoh, Y., Noto, N. and Matsuno, K.: Appraisal of Operative Treatment for Chronic Pancreatitis-with Special Reference to Side-to-Side Pancreaticojejunostomy. Am. J. Surg., 129:621, 1975.

[22]. Traverso, L. W. and Longmire, W. P., Jr.: Preservation of the PylorousDuringPancreaticoduodenectomy: Follow-up Evaluation in 10 Patients. Surg. Gynecol. Obstet., 146:959, 1978.

[23]. Nealon WH, Thompson JC: Progressive loss of pancreatic function in chronic pancreatitis is delayed by main pancreatic duct decompression. A longitudinal prospective analysis of the modified Puestow procedure. Ann Surg 217:458, 1993. 